\title{
Total cavopulmonary and atriopulmonary connections are associated with reduced heart rate variability
}

\author{
G Butera, D Bonnet, L Iserin, D Sidi, J Kachaner, E Villain
}

\begin{abstract}
Aim-To determine whether cavopulmonary connections are associated with abnormalities of heart rate variability. Methods-Heart rate variability was studied by 24 hour Holter monitoring in 39 patients (mean (SD) age 12.2 (4.1) years) who underwent cavopulmonary connection operations (partial in 12, total in 13, and atriopulmonary in 14). Two control groups were used: 18 healthy children (11.1 (2.5) years) and 16 patients (11.7 (4.3) years) undergoing cardiovascular surgery for biventricular repair of congenital heart disease. All patients were in sinus rhythm and had normal left ventricular function. Four time domain indices were calculated: mean duration of $R R$ intervals (RR), standard deviation of all RR intervals (SD), square root of the mean squared differences of successive RR intervals ( $r-M S S D)$, and percentage differences of successive $R R$ intervals of $>50 \mathrm{~ms}$ duration (pNN50). Four frequency domain indices were calculated: total power (TP), low frequency (LF), high frequency (HF), and the LF:HF ratio.

Results-Heart rate variability indices were identical in the two control groups. Significantly reduced heart rate variability was found in patients with total cavopulmonary connections and atriopulmonary connections compared with the two control groups. In patients with partial cavopulmonary connections, heart rate variability was reduced compared with healthy controls. No differences in heart rate variability could be related to clinical status (New York Heart Association functional class), number of surgical interventions, or presence of right atrial enlargement.
\end{abstract}

Service de Cardiologie Pediatrique, 149 Rue de Sevres, 75015 Paris, France

G Butera

D Bonnet

L Iserin

D Sidi

J Kachaner

E Villain

Correspondence to: Dr Butera

email: Gianfra.but@

mailcity.com

Accepted for publication 1 July 1999
The Fontan operation and its variants provide palliative surgical treatment for children with cardiac malformations not suitable for biventricular repair. ${ }^{1}$ Late atrial arrhythmias are a major complication of these operations. ${ }^{2-11}$ Risk factors for atrial arrhythmias identified in clinical series are age at surgery, atrial size, haemodynamic variables, type of Fontan circulation, and duration of follow up. ${ }^{2-11}$ In various cardiovascular diseases, arrhythmias have been shown to be related to alterations of the autonomic nervous system. ${ }^{12}{ }^{13}$ The rich network of autonomic ganglia located in the root of the caval veins and in the myocardium of the right atrium ${ }^{14-16}$ might be damaged during the construction of a cavopulmonary connection. Therefore abnormalities of the balance of the autonomic nervous system may be another important factor in the initiation of arrhythmias in patients with cavopulmonary connections. We therefore studied 39 patients with a cavopulmonary or atriopulmonary connection to determine whether Fontan interventions are associated with abnormalities of heart rate variability.

\section{Methods}

Thirty nine patients with a cavopulmonary connection were recruited to the study over a period of one year. Mean (SD) follow up after surgery was 5.8 (3.4) years. Twelve patients had a partial cavopulmonary connection, 13 a total cavopulmonary connection, and 14 an atriopulmonary connection. All patients were in sinus rhythm with normal atrioventricular (AV) conduction. None had experienced arrhythmias. Systolic function of the univentricular heart evaluated by echocardiography was considered normal. Patients received no antiarrhythmic drugs or drugs known to modify measures of heart rate variability. ${ }^{12}$

A first control group included 18 healthy children referred to our institution to evaluate a history of palpitations. No arrhythmia was found in these subjects. A second control group included 16 patients who underwent biventricular repair for congenital heart disease. All these individuals had a normal 12 lead ECG (except for right bundle branch block in patients with closure of ventricular septal defect) and normal echocardiography. Their data are summarised in tables 1 and 2 .

HOLTER RECORDINGS AND ANALYSIS

All subjects underwent 24 hour Holter monitoring. Two channel recordings (CM1 and CM5) were made. Tacker recorders (Reynolds Medical, St Germain en Laye, France; and Rozinn Electronics, Technimed, Saint Leu la Foret, France) were used. All recordings were analysed by using a Holter analysis system (ELA Medical, Montrouge, France). The data 
Table 1 General characteristics of subjects studied

\begin{tabular}{llllll}
\hline & TCPC & APC & PCPC & $\begin{array}{l}\text { Biventricular } \\
\text { repair }\end{array}$ & $\begin{array}{l}\text { Healthy } \\
\text { controls }\end{array}$ \\
\hline Number & 13 & 14 & 12 & 16 & 18 \\
Age (years) & $11.4(2)$ & $13.8(3.2)$ & $11.2(6.2)$ & $11.9(4.5)$ & $11.1(2.5)$ \\
Age at surgery (years) & $6.6(3.2)$ & $5.6(3.4)$ & $6.7(4.6)$ & $1.6(1.3)^{\star}$ & - \\
Follow up (years) & $4.9(3.4)$ & $7.0(2.8)$ & $4.4(3.3)$ & $10(3.7)^{\star}$ & - \\
NYHA I & 9 & 7 & 5 & 16 & 18 \\
NYHA II & 4 & 6 & 7 & 0 & 0 \\
NYHA III & 0 & 1 & 0 & 0 & 0 \\
NYHA IV & 0 & 0 & 0 & 0 & 0 \\
No RAE & 12 & 1 & 11 & 15 & 0 \\
Moderate RAE & 1 & 2 & 1 & 1 & 0 \\
Severe RAE & 0 & 11 & 0 & 0 & 0 \\
NI < 2 & 5 & 12 & 8 & 15 & 0 \\
NI $>2$ & 8 & 2 & 4 & 1 &
\end{tabular}

Values are $\mathrm{n}$ or mean $(\mathrm{SD})$.

${ }^{\star} \mathrm{p}<0.0001 v$ TCPC, APC, and PCPC.

APC, atrial cavopulmonary connection; NI, number of interventions; NYHA, New York Heart Association functional class; PCPC, partial cavopulmonary connection; RAE, right atrial enlargement; TCPC, total cavopulmonary connection.

Table 2 Congenital heart disease in the subjects studied

\begin{tabular}{lllr}
\hline & TCPC & APC & PCPC \\
\hline Univentricular heart & 6 & 2 & 1 \\
Tricuspid atresia & 4 & 7 & 10 \\
Pulmonary atresia and intact ventricular septum & 1 & 1 & 2 \\
Hypoplastic right ventricle & 1 & 0 & 1 \\
Complete atrioventricular canal with hypoplastic left ventricle & 0 & 3 & 0
\end{tabular}

$\overline{\mathrm{APC} \text {, atrial cavopulmonary connection; PCPC, partial cavopulmonary connection; TCPC, total }}$ cavopulmonary connection.

were reviewed and edited manually by a physician. After classification of QRS configuration, the frequency histogram of RR intervals was displayed and ECG strips of the intervals in both tails of the RR distribution were manually confirmed until no QRS complex was mislabelled as either an artefact or an ectopic beat. Only normal to normal intervals were included. Tapes were eligible only if they had more than 18 hours of analysable data. ${ }^{12}$

HEART RATE VARIABILITY ANALYSIS

The heart rate variability analysis was made using the version 2.00 Elatec (ELA Medical).

Time domain and spectral domain indexes were calculated for the length of the recordings.

Time domain analysis included the following indices: mean duration of $R R$ intervals ( $R R$; $\mathrm{ms}$ ); standard deviation of all RR intervals (SD, $\mathrm{ms}$ ); square root of the mean squared differences of successive RR intervals ( $r-M S S D$, $\mathrm{ms}$ ); and percentage differences between adjacent RR intervals of $>50 \mathrm{~ms}$ duration (pNN50; \%). SD quantifies the variation in heart rate on time intervals ranging from minutes to hours, and is influenced by both short term (respiratory) and long term (physical activity, circadian pattern) changes in heart rate. ${ }^{12}$ pNN50 and r-MSSD estimate short term variations in heart rate variability and predominantly reflect vagal activity. ${ }^{12}$

Spectral measures (frequency domain analysis) were computed using the fast Fourier transform algorithm. To obtain variance reduction, sequential averaging of the spectrum was used. A spectral plot for one hour was the average of the spectra over two minute periods (256 points). A Hanning windowing function was applied to minimise spectral leakage between segments. Power spectra from sequential windowed segments were averaged over each hour and over the entire 24 hours. Spectral plots allowed the identification of two major peaks: a low frequency component (LF, 0.04-0.15 Hz) and a high frequency peak centred around the respiratory frequency $(\mathrm{HF}, 0.15-0.4 \mathrm{~Hz})$. Total power spectrum (TP, $0.01-0.4 \mathrm{~Hz}$ ) and the LF:HF ratio were computed. The power within each band was expressed in $\mathrm{ms}^{2}$. $\mathrm{TP}$ is an expression of the overall variability. ${ }^{12} \mathrm{HF}$ is a marker of vagal activity. ${ }^{12}$ There is disagreement over the LF component. Some investigators regard it as a marker of sympathetic activity while others consider it an index influenced by both sympathetic and vagal systems. ${ }^{12}$ $\mathrm{LF}: \mathrm{HF}$ is considered to reflect sympathovagal balance. $^{12}$

\section{STATISTICAL ANALYSIS}

Data are expressed as frequency for the nominal variables, as medians for the ordinal variables, and as mean (SD) for continuous variables. For each variable, the independence of the observations was controlled by the runs test and the normality of the distribution by using the Wilk-Shapiro test. Nominal variables (sex) were compared using the $\chi^{2}$ test or the Fisher exact test as appropriate. Differences between groups were tested by one way analysis of variance (ANOVA). If the distribution of the variable was not normal or the test for the homogeneity of the variance gave a significant result, we used the Kruskal-Wallis test. If a significant $\mathrm{p}$ value was obtained, post-hoc comparisons were made using the Tukey's HSD multiple range test or the non-parametric test for multiple comparisons. All tests were two sided. A p value $<0.05$ was considered significant.

\section{Results}

PATIENT CHARACTERISTICS

The groups studied did not differ in age and sex distribution. Age at surgery was lower in the patients who underwent biventricular repair (table 1).

HEART RATE VARIABILITY IN GROUPS STUDIED These results are shown in table 3 . In patients with a total cavopulmonary connection, all heart rate variability indices except $R R$ and LF:HF were significantly reduced compared with healthy controls or with children who had a biventricular repair, showing a strong reduction in the autonomic nervous system tone with low vagal drive (reduction of r-MSSD, pNN50, and $\mathrm{HF}$ ).

Patients with an atriopulmonary connection had a significant reduction in heart rate variability compared with control subjects (reduction of SD, r-MSSD, pNN50, TP, LF, and $\mathrm{HF}$ ) and a reduced vagal drive compared with surgical patients (reduction of r-MSSD, pNN50, and HF).

Patients with partial cavopulmonary connection showed reduced variability compared with healthy subjects (reduction of r-MMSSD, pNN50, TP, LF, and HF).

Surgical patients did not differ from healthy children. 
Table 3 Indices of heart rate variability in the groups studied

\begin{tabular}{llllll}
\hline & TCPC & APC & PCPC & Biventricular repair & Healthy controls \\
\hline RR (ms) & $698(99)$ & $752(64)$ & $700(100)$ & $790(155)$ & $845(134)$ \\
SD (ms) & $94(31)^{\star}$ & $121(31) \dagger$ & $121(44) \dagger$ & $153(60)$ & $170(43)$ \\
r-MSSD (ms) & $22.6(9.7)^{\star}$ & $29(22)^{\star}$ & $34.5(15) \dagger$ & $69(45)$ & $75(36)$ \\
pNN50 (\%) & $3.6(4.8)^{\star}$ & $6(9)^{\star}$ & $8.8(5.7) \dagger$ & $25(13)$ & $32(13)$ \\
TP $\left(\mathrm{ms}^{2}\right)$ & $760(980)^{\star}$ & $972(718) \dagger$ & $1925(1590) \dagger$ & $3062(2400)$ & $6550(5000)$ \\
LF $\left(\mathrm{ms}^{2}\right)$ & $159(210)^{\star}$ & $176(156)^{\star}$ & $531(550) \dagger$ & $775(548)$ & $1862(1418)$ \\
HF $\left(\mathrm{ms}^{2}\right)$ & $65(117)^{\star}$ & $98(120)^{\star}$ & $244(240) \dagger$ & $659(637)$ & $1443(2039)$ \\
LF/HF & $3.1(2.25)$ & $3.0(2.0)$ & $2.8(2.6)$ & $1.75(0.9)$ & $2.0(0.8)$ \\
\hline
\end{tabular}

Values are mean (SD).

${ }^{\star} \mathrm{p}<0.0001 v$ biventricular repair and healthy controls; $\mathrm{tp}<0.0001 v$ healthy controls.

APC, atrial cavopulmonary connection; HF, high frequency $\left(\mathrm{ms}^{2}\right) ; \mathrm{LF}$, low frequency $\left(\mathrm{ms}^{2}\right) ; \mathrm{LF} / \mathrm{HF}, \mathrm{LF}$ to $\mathrm{HF}$ ratio; PCPC, partial cavopulmonary connection; pNN50, per cent of differences of successive RR intervals > $50 \mathrm{~ms}$; r-MSSD, square root of the mean squared differences of successive RR intervals ( $\mathrm{ms}$ ); RR, mean duration of RR intervals (ms); SD, standard deviation of all RR intervals (ms); TCPC, total cavopulmonary connection; TP, total power $\left(\mathrm{ms}^{2}\right)$.

No differences in heart rate variability indices were observed between the three subgroups of cavopulmonary connection with respect to the number of surgical interventions before the Fontan operation, right atrial enlargement, or New York Heart Association functional class (data not shown).

\section{Discussion}

Cavopulmonary connection has largely been done for palliation where there is a univentricular heart. ${ }^{1}$ Atrial arrhythmias and sinoatrial disease are frequent complications of cavopulmonary connections. ${ }^{2-810}$ Risk factors which have been so far studied include older age at surgery, duration of follow up, right atrial enlargement, increased mean pulmonary artery pressure, and atrioventricular valve regurgitation. ${ }^{2-4}{ }^{6}{ }^{10}$ Beside surgical and haemodynamic risk factors, the autonomic nervous system could play an important role in the initiation of arrhythmias. ${ }^{12}{ }^{13}$ Reduction in vagal activity and an increase in sympathetic tone have been found to be associated with supraventricular tachycardias, ${ }^{13}$ ventricular tachycardias, ${ }^{13}$ and ventricular fibrillation. ${ }^{13}$ In addition, an autonomic imbalance has been shown to be an important risk factor for mortality after myocardial infarction..$^{13} 17$

Analysis of heart rate variability is widely used in adult cardiovascular disease to obtain quantitative markers of autonomic nervous system function. ${ }^{12}$ The predictive value of heart rate variability for late mortality in these diseases is similar to the left ventricular ejection fraction, while it is better at predicting life threatening arrhythmias. ${ }^{18-20}$ Reduced heart rate variability has also been identified as a prognostic factor in cardiomyopathies, ${ }^{12}$ heart transplantation, ${ }^{12}$ diabetic neuropathy, ${ }^{12}$ and congestive heart failure. ${ }^{12}$

Various factors have been reported to be responsible for the reduction of heart rate variability. These include drugs, ${ }^{12}$ such as flecainide, encainide, propafenone, and $\beta$ blockers, all of which may affect heart rate variability indices. None of our patients received any treatment known to influence heart rate variability. Second, reduced heart rate variability has been found in patients with severe myocardial dysfunction. ${ }^{12}$ All the patients in our series had normal ventricular function. Third, heart surgery and cardiopulmonary bypass are associated with transient imbalance of the autonomic nervous system. ${ }^{21-23}$ In adults undergoing coronary artery grafting there is a transient reduction in heart rate variability that improves within a month of the intervention. ${ }^{21}$

There are few data on modifications of the autonomic nervous system after cardiac surgery for congenital heart disease. Finley et al showed that heart rate variability in children with atrial septal defects improved after surgery. ${ }^{22}$ In our series, patients with a total cavopulmonary connection or an atriopulmonary connection had a markedly reduced heart rate variability and low vagal drive. In patients with a partial cavopulmonary connection, reduced variability was found only in comparison with healthy controls. These alterations in heart rate variability in patients with cavopulmonary connections could not have been caused by heart surgery or by cardiopulmonary bypass as the average delay between surgery and the heart rate variability study was as long as 5.8 (3.4) years. These patients should therefore have recovered from any transient autonomic nervous system damage. In addition, the control group of patients who underwent cardiovascular surgery for biventricular repair of congenital heart disease had normal heart rate variability.

As no known factors influencing heart rate variability could be identified in our patients, we hypothesise that surgery to the caval veins and right atrium, as in cavopulmonary connection operations, may alter the intracardiac nervous system. Recent studies ${ }^{14}$ have shown that the largest populations of cardiac ganglia are located close to the sinoatrial and atrioventricular nodes. Other important collections of ganglia are present in the interatrial septum, at the atrial appendage-atrial junctions, at the junction of the superior vena cava with the right atrium, and in the superior and anterior wall of the right atrium. ${ }^{14-16}$ Postganglionic fibres from these ganglia innervate the atrioventricular node and the sinoatrial node. These fibres extend dorsally around the superior vena cava to the sinus node, into the free wall of the right atrium, and through the mid- and anterior portions of the low interatrial septum. ${ }^{15}{ }^{16}$ The integrity of this network, along with the extracardiac autonomic nervous system, plays an important role in the maintenance of the electrical stability of the heart. ${ }^{14}{ }^{15}{ }^{24-26}$ In adult heart transplants, increased sinus rhythm recovery, decreased atrial 
arrhythmia frequency, and reduced mortality were reported when a bicaval anastomosis technique was used compared with the standard procedure of atrial anastomosis. ${ }^{27} 28$ This could be related to the preservation of the intracardiac autonomic network, leading to better electrical stability and faster reinnervation. ${ }^{1427}{ }^{28}$ In our patients, cavopulmonary connections may have altered the intracardiac ganglia and the postganglionic fibres, leading to diminished electrical stability, compromising the substrate for neural processing, and reducing the beneficial effects on sinus node function. This alteration is particularly evident in atriopulmonary and total cavopulmonary connections, in which there is major involvement of areas containing the intracardiac autonomic nervous system. Conversely, in patients with a partial cavopulmonary connection, the alteration in heart rate variability is less important because only ganglia at the root of the superior vena cava are likely to be damaged.

The main limitation of our study is that we did not demonstrate the relation between abnormalities of heart rate variability and the occurrence of rhythm disturbances in cavopulmonary connections. However, dysfunction of the autonomic nervous system might be a risk factor for arrhythmias in these patients. Therefore surgical strategies preserving the intracardiac autonomic nervous system should be considered. We have shown here that partial cavopulmonary connection leads to less altered heart rate variability, probably because damage to the intracardiac autonomic nervous system is reduced. Similarly, the construction of a total cavopulmonary connection by using an extracardiac conduit might also preserve intracardiac ganglia, but further studies are needed to resolve these issues.

1 Kirklin J W, Barrat-Boyes BG. Cardiac surgery. New York: Churchill Livingstone, 1993:1065-78.

2 Wren C. Late postoperative arrhythmias. In: Wren C, Campbell RWF, eds. Paediatric cardiac arrhythmias. Oxford: Campbell RWF, eds. Paediatric cardiac ar

3 Weber HS, Hillebrand WE, Kleinman CS, et al. Predictors of rhythm disturbances and subsequent morbidity after the Fontan operation. Am f Cardiol 1989;64:762-7.

4 Gewillig M, Wise RK, de Leval MR, et al. Early and late arrhythmias after the Fontan operation: predisposing factors and clinical consequences. Br Heart f 1992;67:729.

5 Balaji S, Gewillig M, Bull C, et al. Arrhythmias after the Fontan procedure: comparison of total cavopulmonary connection and atriopulmonary connection. Circulation 1991;84(suppl III):III-162-7.

6 Gelatt H, Hamilton RM, McCrindle BW, et al. Risk factors for atrial arrhythmias after Fontan operation. $\mathcal{F} \mathrm{Am}$ Coll Cardiol 1994;24:1735-41.
7 Gardiner HM, Dhillonrami J, Bull C, et al. Prospective study of the incidence of determinants of arrhythmias after total cavopulmonary connection. Circulation 1996;94(suppl II):II-17-21

8 Kawey REW, Gaum WE, Byrum CJ, et al. Loss of sinus hythm after total cavopulmonary connection. Circulation 1995;92 (suppl II):II-304-8.

9 Manning PB, Mayer JE, Wernovsky G, et al. Staged operation to Fontan increases the incidence of sinoatrial node dysfunction. F Thorac Cardiovasc Surg 1996;111:833-40.

10 Fishberger SB, Wernovsky G, Gentles TL, et al. Factors that influence the development of atrial flutter after the Fontan operation. F Thorac Cardiovasc Surg 1997;113:80-6.

11 Kao JM, Alejos JC, Grant PW, et al. Conversion of atriopulmonary to cavopulmonary anastomosis in management of late arrhythmias and atrial thrombosis. Ann Thorac Surg 1994;58:1510-14.

12 Task force of the European Society of Cardiology and the North American Society of Pacing and Electrophysiology. Heart rate variability. Standards of measurements, physiological interpretation and clinical use. Circulation 1996;93: ological inter $1043-65$.

13 Schwartz PJ, Priori SG. Sympathetic nervous system and cardiac arrhythmias. In: Zipes DP, Jalife J, eds. Cardiac electrophysiology. From cell to bedside. Philadelphia: WB Sanders, 1990:330-40.

14 Singh S, Johnson PL, Lee RE et al. Topography of cardiac ganglia in the adult human heart. F Thorac Cardiovasc Surg 1996;112:943-953.

15 Kocovic DZ, Harada T, Shea JB, et al. Alterations of heart rate and heart rate variability after radiofrequency catheter ablation of supraventricular tachycardia. Delineation of parasympathetic pathways in the human heart. Circulation 1993;88:1671-81.

16 Randall WC, Wurster RD, Duff RD, et al. Surgical interruption of post-ganglionic innervation of the sino-atrial region. f Thorac Cardiovasc Surg 1991;101:66-74.

17 Schwartz PJ. The autonomic nervous system and sudden death. Eur Heart f 1998;19(suppl F):72-80.

18 Kleiger RE, Miller JP, Bigger JT, et al, and the Multicenter Post-Infarction Research Group. Decreased heart rate variability and its association with increased mortality after acute myocardial infarction. Am f Cardiol 1987;59:256-62.

19 Bigger JT, Fleiss JL, Steinman RC, et al. Frequency domain measures of heart rate variability and mortality after myocardial infarction. Circulation 1992;85:164-71.

20 Odemuyiwa O, Malik M, Farrell T, et al. Comparison of the predictive characteristics of heart rate variability index and left ventricular ejection fraction for all-cause mortality, arrhythmic events and sudden death after acute myocardial infarction. Am f Cardiol 1991;68:434-9.

21 Komatsu T, Kimura T, Nishiwaki K, et al. Recovery of heart rate variability profile in patients after coronary artery surgery. Anesth Analg 1997;85:713-18.

22 Finley JP, Nugent ST, Hellebrand W, et al. Sinus arrhythmia in children with atrial septal defect: an analysis of heart rate variability before and after surgical repair. Br Heart $\mathcal{F} 1989$; 61:280-4.

23 Brembilla-Perrot B, Jaquemin L, Danchin $\mathrm{N}$, et al. Alteration de la variabilité sinusale après chirurgie cardiaque. Ann Cardiol Angeiol 1998;47:149-54.

24 Ardell JL. Structure and function of mammalian intrinsic cardiac neurons. In: Armour JA, Ardell JL, eds. Neurocardiology. New York: Oxford University Press, 1994:95-114.

25 Armour JA. Peripheral autonomic neuronal interactions in cardiac regulation. In: Armour JA, Ardell JL, eds. Neurocardiology. New York: Oxford University Press, 1994:219-44.

26 Horackova M, Armour JA. Role of peripheral autonomic neurones in maintaining adequate cardiac function. Cardiovasc Res 1995;30:326-35

27 Bernardi L, Valenti C, Wdowczyck-Szulc J, et al. Influence of type of surgery on the occurrence of parasympathetic reinnervation after cardiac transplantation. Circulation 1998;97:1368-74.

$28 \mathrm{El} \mathrm{Gamel} \mathrm{A,} \mathrm{Yonan} \mathrm{NA,} \mathrm{Ramman} \mathrm{AN,} \mathrm{et} \mathrm{al.} \mathrm{The} \mathrm{clinical}$ benefit of the bicaval technique for cardiac transplantation. f Thorac Cardiovasc Surg 1995;109:1257-9. 